\title{
Pressure Monitoring of Diesel Engine Crankcase Gases for Integrated
} Diagnostics

\author{
${ }^{1}$ Ilnur R. Akhmetzianov, ${ }^{2}$ Alexandr T. Kulakov, ${ }^{3}$ Damir I. Nuretdinov \\ ${ }^{1-3}$ Kazan Federal University \\ Email: nuretddamir@yandex.ru
}

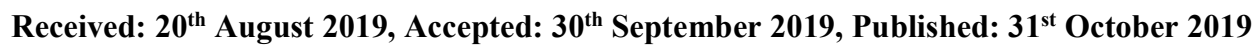

\begin{abstract}
The paper presents an analysis of methods for monitoring the flow and pressure of crankcase gases, a method for measuring the pressure of crankcase gases using the built-in diagnostic system. The authors investigated the prospects, advantages and disadvantages of the method of diagnosing an engine by the flow rate and pressure of crankcase gases, the algorithm for creating an integrated diagnostic system. Based on studies of measurement methods, a number of recommendations are proposed for its further improvement and the selection of modern measuring instruments. Improving the methods for diagnosing aggregates and units is one of the most important areas for ensuring their performance. Therefore, built-in diagnostics should be given special attention in the production and operation of transport-technological machines, which determines the relevance of this area of research.

Determination of the technical condition of the units and components of the car by diagnostic parameters every day becomes relevant. Especially this problem concerns the reliability of automotive internal combustion engines, the state of which requires constant monitoring of technical parameters in operation.

The article focuses more on technology and means for measuring crankcase pressure.

The materials of the article are of practical value and can be used in the educational process of a technical university and at motor transport enterprises, scientific and technical centers, car repair plants. The development of a system for monitoring the technical condition of the engine is being carried out as part of the on-board diagnostics of production equipment of PJSC KAMAZ .
\end{abstract}

Keywords

Diesel Engine, Cylinder-Piston Group, Diagnostics, Crankcase Gas Consumption, Pressure.

\section{Introduction}

One of the nodes that determine the reliability of the engine is a cylinder-piston group (CPG). Engine operation should be stopped immediately in the event of extreme wear on the CPG, especially if the rings break. Therefore, the task of accurately determining the degree of deterioration of the CPG during operation by diagnostic parameters is very relevant and avoids further consequences.

In the field of assessing the technical condition of the engine using diagnostic parameters, as well as improving the methodology for their measurement, studies are being conducted by Russian and foreign scientists, which are presented in [2] - [9].

There are many ways to assess the technical condition of an engine. In bench conditions, engine torque, specific fuel consumption, oil consumption for burning, crankcase gas pressure, coolant temperature, oil pressure and temperature in the lubrication system, pressure and charge air temperature can be measured. Some of these parameters accurately assess the condition of the nodes, however, a system for measuring them is not integrated into the power unit.

\section{Methods}

Diagnosis in stationary conditions does not fully solve the problem of optimal recovery of the vehicle's performance, since the main requirement - to service the vehicle on demand — is fulfilled here with only a certain probability. This situation is most typical for cars operating in isolation from maintenance bases and being in personal use. In addition, the use of stationary and portable diagnostic tools, as a rule, is associated with the operations of connecting, configuring and removing sensors and switching fittings, which leads to significant labor costs for auxiliary work. They make up to $80-85 \%$ of the time of the full cycle of diagnosis. These shortcomings can be largely eliminated by the introduction of integrated diagnostics. Built-in diagnostics can be implemented in two ways: by installing special sensors built into the corresponding vehicle systems with outputting signals to control points, for example, a plug connector; the car's equipment with sensors and additional measuring instruments that provide continuous information to the driver about the technical condition of the vehicle's components and assemblies [1].

As practice shows, the engine resource is determined by the state of the crank mechanism and the cylinder-piston group. When the liner and piston wheels wear, also when the rings break, the flow of bursting gases into the crankcase increases. The degree of breakthrough of gases into the crankcase can be measured by its quantity over a certain time interval or by the pressure of gases in the crankcase.

The amount of gases breaking into the crankcase in the conditions of motor transport enterprises and service 
centers can be determined by the gas consumption indicator KI-13671 GOSNITI. During the operation of the engine before repair, the crankcase gas consumption increases 2-4 times [2].

The main factors influencing crankcase gas consumption are: engine load, engine hours, environmental parameters (temperature, humidity, pressure), crankshaft rotation speed, quality of engine oil, coolant temperature. These factors must be incorporated into the crankcase gas flow measurement algorithm.

According to [2], in the initial period of operation for the YaMZ-238 engine, crankcase gas consumption is $651 /$ min, the maximum permissible value is $1801 / \mathrm{min}$ (when measured without load). That is, the maximum permissible value is 2.7 times greater than in the initial period of operation.

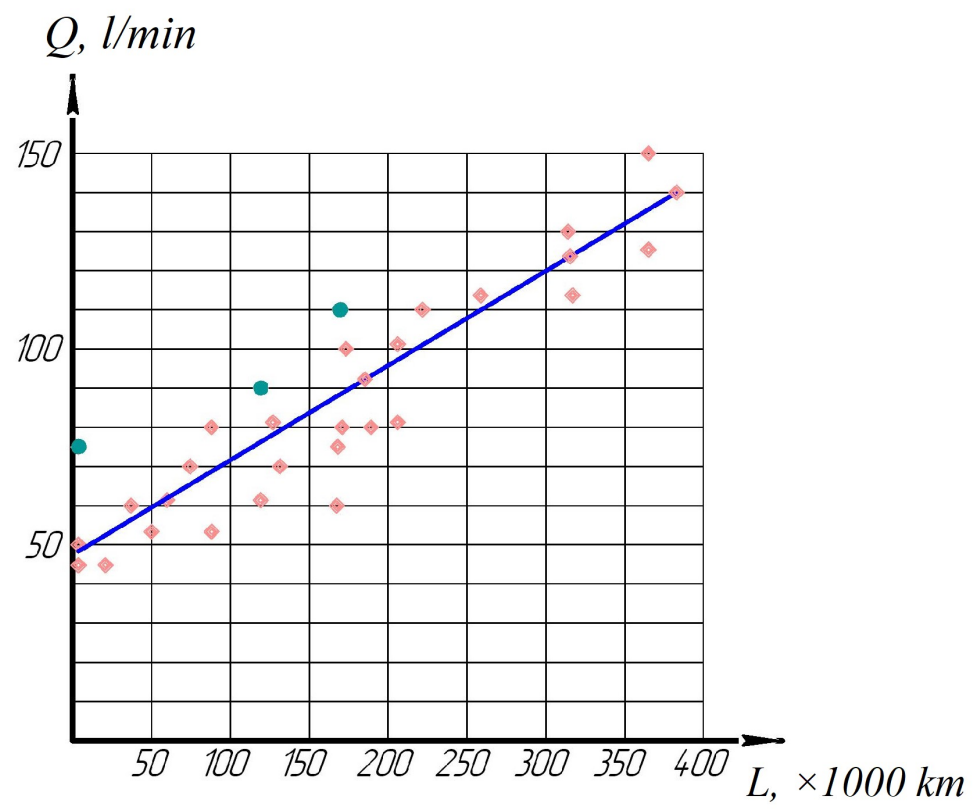

Figure 1: Dependence of Crankcase Gas Consumption on the Operating Time of the YaMZ-238 Engine [2]

The pressure of the crankcase gases increases in proportion to their flow rate. The pressure in the crankcase is not high, therefore it is recommended to use a water differential pressure gauge for measurement in bench conditions (Fig. 2, a). The pressure gauge is a pair of glass tubes 2 with a diameter of 5-10 mm and a length of $30-50 \mathrm{~cm}$, connected at the bottom by a piece of rubber tube 3 in the form of the letter "U" and scale 2 . All is mounted on a suitable wooden plank. Water is poured into the tubes.

The schemes for installing a differential pressure gauge on the engine can be different depending on the design features of the engine (Fig. 2, b, d) [10]. In the case of measurement through the oil filler neck, a special adapter is used, which is installed instead of the cover (Fig. 2, c).
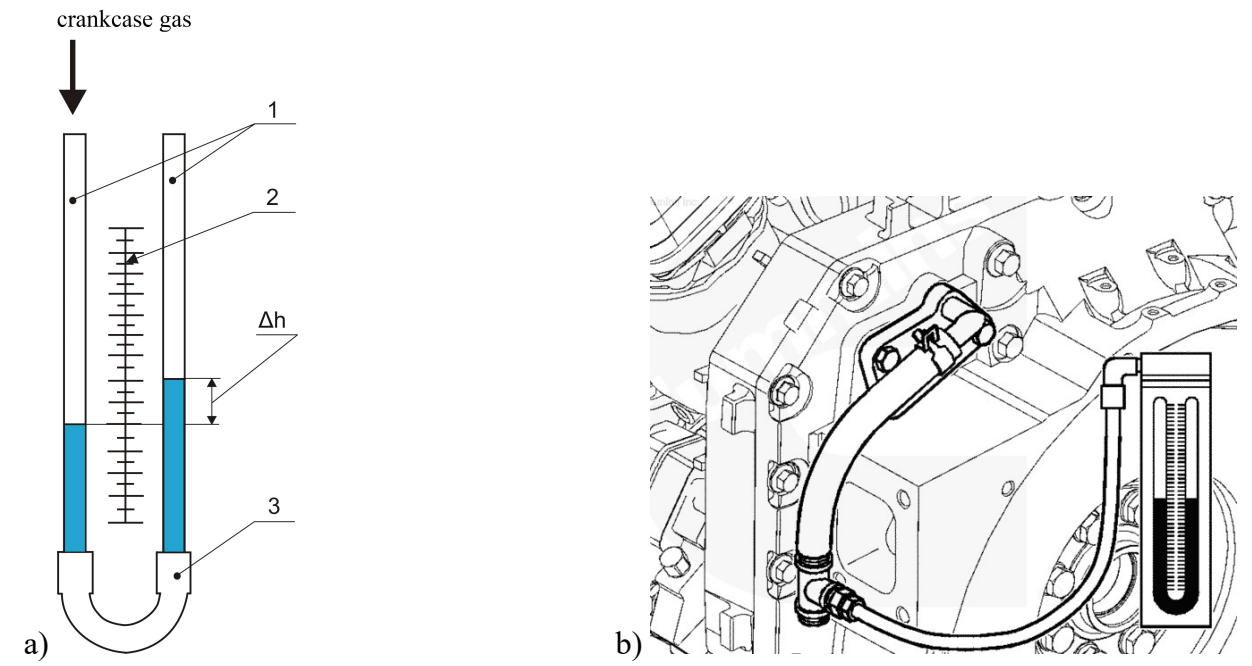
c)

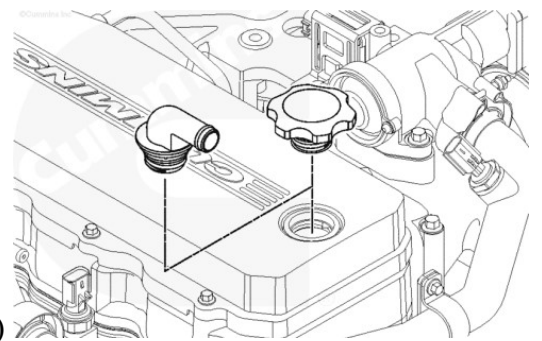

d)

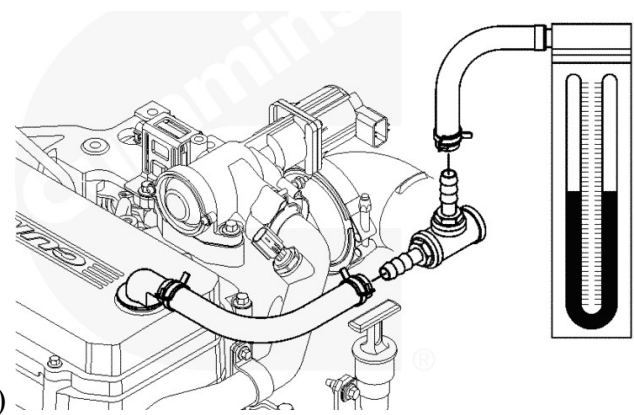

Figure 2: Options for Installing a Differential Pressure Gauge on the Engine: a) Differential Pressure Gauge; b) Installation at the End of the Crankcase Breather Tube; c) The Installation of an Adapter instead of the Cap of the Lubrication System; d) Installation of the Gauge to the Output Fitting Adapter

[10]

It is advisable to measure diagnostic parameters during bench tests under the following conditions: coolant temperature at the engine outlet $80-95^{\circ} \mathrm{C}$, nominal speed of the crankshaft, no engine load, tof the oil temperature in the main oil line no more than $95^{\circ} \mathrm{C}$, inlet air temperature $25 \pm 3{ }^{\circ} \mathrm{C}$.

The distance between the water levels $\Delta \mathrm{h}$ in the tubes with the engine running should not exceed 50-70 mm. A large pressure value, with a normal amount of crankcase gases, indicates a malfunction of the CPG or KShM, also a clogged crankcase ventilation system or a malfunction of the non-return valve in this system.

Table 1 shows the pressure values when measuring with a differential pressure gauge corresponding to the crankcase gas flow rate (with a calibrated hole diameter of $7.67 \mathrm{~mm}$ ) of the Cummins engine [10].

\begin{tabular}{|c|c|c|}
\hline No. & $\begin{array}{c}\text { Pressure } \\
\text { mm water column }\end{array}$ & $\begin{array}{c}\text { Gas consumption, } \\
1 / \mathrm{min}\end{array}$ \\
\hline 1. & 25.4 & 50 \\
\hline 2. & 50.8 & 84 \\
\hline 3. & 76.3 & 103 \\
\hline 4. & 101.6 & 119 \\
\hline 5. & 127 & 133 \\
\hline 6. & 152.4 & 145 \\
\hline 7. & 177.8 & 155 \\
\hline 8. & 203.2 & 164 \\
\hline 9. & 228.6 & 172 \\
\hline 10. & 254 & 180 \\
\hline 11. & 279.4 & 187 \\
\hline 12. & 304.8 & 193 \\
\hline 13. & 330.2 & 200 \\
\hline 14. & 355.6 & 206 \\
\hline 15. & 381 & 211 \\
\hline 16. & 406.4 & 217 \\
\hline 17. & 431.8 & 222 \\
\hline 18. & 457.2 & 226 \\
\hline 19. & 482.6 & 229 \\
\hline 20. & 508 & 235 \\
\hline 21. & 533 & 239 \\
\hline 22. & 558.8 & 242 \\
\hline 23. & 584.2 & 246 \\
\hline 24. & 609.6 & 248 \\
\hline
\end{tabular}

Table 1: Ratio of Pressure and Flow of Crankcase Gases on the Engine Cummins [10]

As the research results show, the ratio of crankcase pressure and crankcase gas flow has a linear relationship. Crankcase gas pressure meets all requirements related to diagnostic parameters, such as uniqueness, stability, informational content and sensitivity.

Despite the advantages of the diagnostic parameter, even modern engines of domestic production do not have an on-board diagnostic system for crankcase pressure.

The use of the differential pressure gauge for integrated diagnostics is impossible, therefore, the considered 
measurement method can only be used in bench conditions at engine manufacturing or in motor transport enterprises during maintenance and repair.

To monitor the crankcase gas pressure with integrated diagnostics, the engine must be equipped with a pressure sensor that transmits information to the electronic control unit (ECU). Depending on the load mode and environmental conditions in the computer, the obtained current pressure value is compared with the maximum permissible value stored in the computer memory during tuning. If the value is exceeded, the ECU signals the need for shutting down the operation and taking the necessary measures to eliminate the malfunction.

Figure 3 shows the installation diagram of the sensor on the KAMAZ engine.

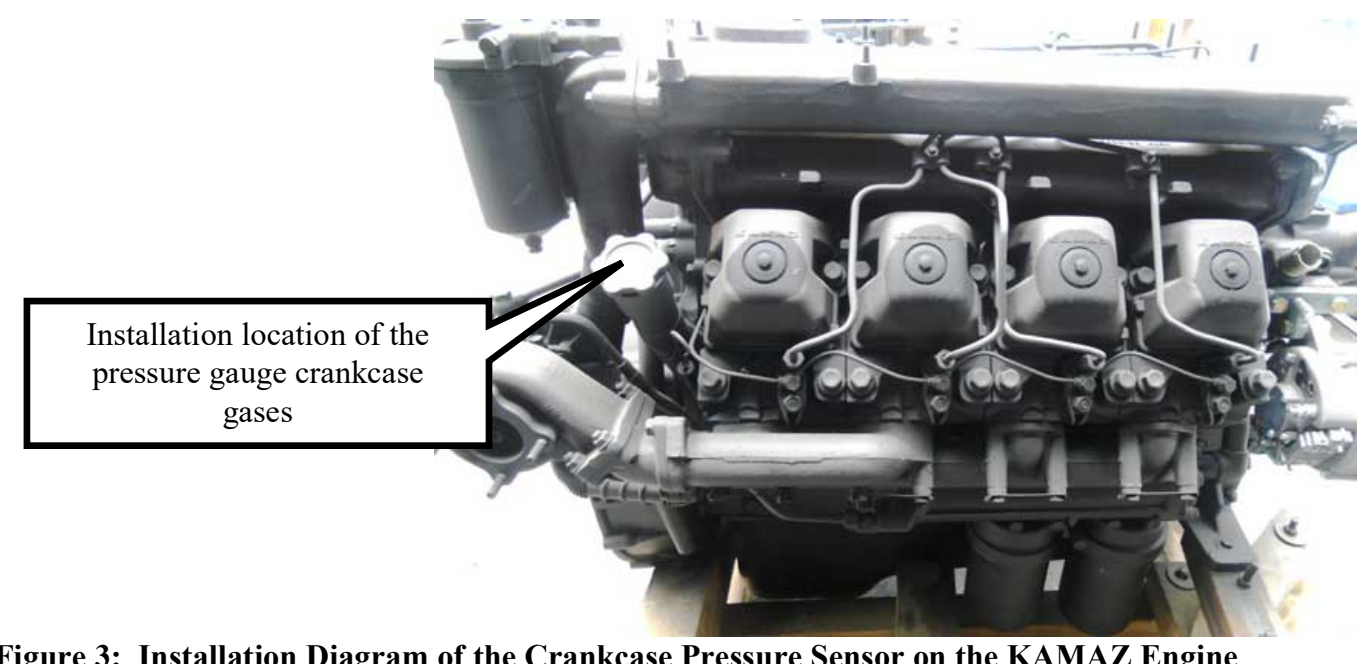

Figure 3: Installation Diagram of the Crankcase Pressure Sensor on the KAMAZ Engine

The crankcase pressure control system is used on engines of foreign trucks. Figure 4a shows a 3-pin crankcase gas pressure sensor Volvo D12D / RVI, with a pressure measurement range of 40-140 kPa, used on Volvo and Renault trucks. It should be noted that this sensor has a low sensitivity to pressure changes in the crankcase.

The PD100I type sensors with a measured pressure range from $0.2 \mathrm{kPa}$ to $100.0 \mathrm{kPa}$ have good sensitivity to pressure changes (Fig. 4, b). They are pressure transmitters with an open measuring silicon crystal of the sensor and cable entry of the standard EN175301-803 (DIN43650 A) [12].

b)

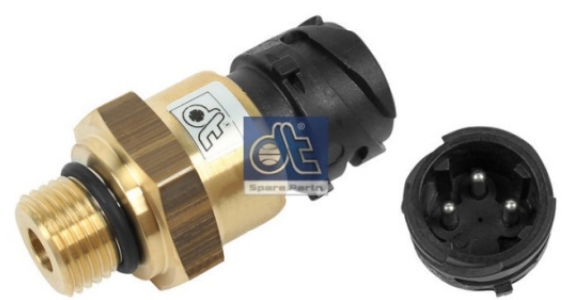

a)

Figure 4: Pressure Sensors: a) Volvo D12D / RVI Crankcase Pressure Sensor; b) PD Type 100 Sensor [11, 12]

Results and Discussion

Studies have shown that crankcase gas pressure can be used as a diagnostic parameter to assess the technical condition of the engine piston group.

\section{Summary}

To develop an integrated automated control system for a specific engine, a number of tasks need to be solved: - determine in bench conditions the pressure values of crankcase gases for a new engine after passing the breakin period. For accurate results, use a differential pressure gauge.

- according to the test results to determine the pattern of change in pressure and flow rate of crankcase gases. Estimate the maximum permissible pressure values during accidental wear of the CPG, with the scuff of the CPG, with the scuff of the bearings KShM.

- select a pressure sensor for the nominal and maximum permissible value.

- record the change in the sensor reading at various crankcase pressure values. 
- enter in the memory of the computer an indication corresponding to the maximum permissible value.

- connect the pressure sensor to the engine ECU.

- display on the car dashboard a device signaling a malfunction, for example, a signal in the form of a STOP sign.

\section{Conclusions}

The use of an integrated crankcase pressure monitoring system prevents engine failures associated with wear of the piston-cylinder group. Modern sensors with high accuracy allow you to monitor pressure changes during the operational period.

\section{Acknowledgments}

The work is performed according to the Russian Government Program of Competitive Growth of Kazan Federal University.

\section{References}

[1] A.G. Sergeev. Diagnosis of electrical equipment of cars: a training manual / A.G. V.E. Sergeev. Yutt. Moscow: Transport, 1987. - 159 pages.

[2] E.V. Nikolaev. Improving the technology for diagnosing a cylinder-piston group of a diesel engine by crankcase gas parameters: Abstract. diss. Cand. tech. Sciences 05.20.03. - Moscow, 2013. - 17 pages.

[3] Raman Autar. An Automated Diagnostic Expert System for Diesel Engines // Journal of Engineering for Gas Turbines and Power, vol. 118, No. 3, pp. 673-679, 1996.

[4] Diagnosis and operational control of the residual life of components and assemblies of the car. I.V. Makarova, A.T. Kulakov, E.M. Mukhametdinov, L.M. Habsalikhova, A.V. Vasiliev. / Transport: science, technology, management. - 2018. - No. 2. - pp. 54-60.

[5] E.P. Barylnikova, A.T. Kulakov, O.A. Kulakov. Adaptive system of supplying lubricant to the internal combustion engine, IOP Conference Series: Materials Science and Engineering, vol. 240, No. 1, 2017. https://repository.kpfu.ru/?p_id=171075

[6] E.V. Nistratova, N.S. Nistratova. The consumption of crankcase gases reflects the technical condition of the engine's CPG // Technique and equipment for the village. - 2011. - No. 9. - pp. 41-21.

[7] E. Tsybunov, K. Shubenkova, P. Buyvol, E. Mukhametdinov. Interactive (intelligent) integrated system for the road vehicles diagnostics, Lecture Notes of the Institute for Computer Sciences, Social-Informatics and Telecommunications Engineering, vol. 222, pp. 195-204, 2018.

[8] Sh. Alaviyoun, MA Ehteram. Performance study of a diaphragm type crankcase pressure control valve, The Journal of Engine Research, vol. 30, pp. 47-54, 2013.

[9] K.F. Abramek. Measurements of maximum crankcase pressure for evaluation of the piston-rings- cylinder assembly, Journal of KONES Powertrain and Transport, vol. 16, No. 2, pp. 23-28, 2009.

[10] Repair Manual Cummins ISF 2.8 - https://diesel-inj.ru/manuals/131/1889. - (Date of treatment 01/29/2019).

[11] Crankcase pressure sensor VOLVO D12D / RVI 3-pin - https://auto-part.ru/catalog/diesel-technic/92274. (accessed on 01/29/2019).

[12]OVEN general industrial pressure sensors for the main PD100I productions. http://old.owen.ru/catalog/preobrazovateli_na_nizkie_davleniya_pd100/ 20539822. (Date of treatment 01/29/2019). 